\title{
RAGAM ORNAMEN ATAP KLENTENG JIN DE YUAN SEBAGAI SALAH SATU ASET DI KAWASAN KOTA TUA
}

\author{
Polniwati Salim \\ Jurusan Desain Interior, School of Design, BINUS University \\ Jln. K.H. Syahdan No. 9, Palmerah, Jakarta Barat 11480 \\ Polnilim@binus.ac.id
}

\begin{abstract}
The Plurality of cultures in the country of Indonesia can be seen from the diverse ethnics and tribal minorities and the majorities either. The numbers of Klenteng/temple as one of the places of worship of minority Chinese community which has now been given freedom by the government of Indonesia, are still very few. Jin De Yuan Klenteng is one of the mainstay of tourism in the Area Chinatown, Glodok who entered the Old City area in the world. Therefore, the aesthetic value in the pagoda is very important to be raised in order to remain attractive as a tourism asset. How the application of aesthetic elements on the exterior of Jin De Yuan temple, and any decoration is used, by looking at the positive side of social relationships and cultural preservation, is the point that must be noticed and developed by all of us.
\end{abstract}

Keywords: klenteng building, aesthetics value, the exterior ornament

\begin{abstract}
ABSTRAK
Pluralitas kebudayaan di negara Indonesia dapat terlihat dari beragam etnik maupun suku baik minoritas maupun mayoritas. Klenteng sebagai salah satu tempat ibadah masyarakat minoritas Tionghoa yang kini telah diberikan kebebasan oleh pemerintah Indonesia, jumlahnya masih sangat sedikit. Dan Klenteng Jin De Yuan merupakan salah satu andalan wisata di Kawasan Pecinan, Glodok yang masuk dalam kawasan Kota Tua di dunia. Oleh sebab itu nilai estetis dalam klenteng sangat penting untuk dimunculkan agar tetap menarik sebagai aset wisata. Bagaimana penerapan elemen estetika pada eksterior bangunan kelenteng Jin de Yuan, dan ragam hias apa saja yang digunakan, dengan melihat sisi yang positif dari hubungan sosial budaya serta pelestariannya, menjadi hal yang perlu diperhatikan dan dikembangkan.
\end{abstract}

Kata kunci: bangunan klenteng, nilai estetis, ornamen eksterior 


\section{PENDAHULUAN}

Kelenteng Jin de Yuan (Kelenteng Kim Tek Ie) berada di Jl. Kemenangan III No. 13 (Petak 9), Glodok, Jakarta Barat, Indonesia. Dilihat segi Feng Shui, arah Bangunan Kelenteng ini menghadap Selatan, berada diantara aliran Kali Besar dan Kali Ciliwung. Seluruh bangunan di cat warna merah seperti api dan darah yang melambangkan keberuntungan dan kesejahteraan.

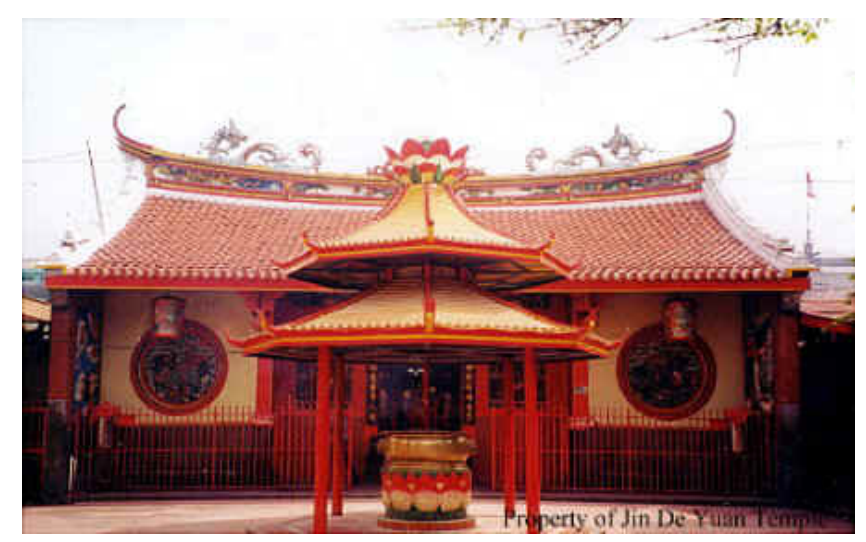

Gambar 1 Fasad Klenteng Jin De Yuan

\section{Makna Ornamen}

Tampak luar klenteng terlihat banyak sekali ornamen yang menghiasi seluruh bangunan mulai dari atap, dinding, jendela, gapura hingga kolom dan umpak. Namun sebelumnya mari kita lihat dulu, bagaimana makna yang terkandung dalam ornamen sebuah klenteng. Makna yang terkandung pada ornamen-ornamen dalam sebuah kelenteng tidak akan terlepas hubungannya dengan faktor/segi kehidupan manusia sehari-hari. Bila dikaitkan dalam hubungannya dengan klenteng, maka terdapat tiga faktor yang mempengaruhinya.

Pertama, ornamen sebagai seni dalam kebudayaan. Ada tujuh unsur kebudayaan yang meliputi bahasa, sistem teknologi, sistem mata pencaharian, organisasi sosial, sistem pengetahuan, religi, dan kesenian. Dari ketujuh unsur tersebut bila dikaitkan hubungannya dengan ornamen maka ornamen termasuk dalam unsur kesenian. Ornamen sebagai seni dalam suatu kebudayaan merupakan segala ekspresi hasrat manusia akan keindahan, dan keindahan itu sendiri adalah suatu konsep abstrak yang dapat dinikmati melalui konteks tertentu.

Kedua, ornamen sebagai simbol-simbol religi suatu budaya. Menurut pernyataan Spradley dalam Sobur (2004), mengatakan bahwa semua makna budaya diciptakan dengan menggunakan simbol-simbol dan makna hanya dapat disimpan dalam simbol. Memahami ornamen sebagai simbolsimbol budaya dan religi, sangat terkait dengan kontekstual masyarakat dan kebudayaan sendiri.

Ketiga, ornamen sebagai ideologi. Ornamen dalam hubungannya dengan ideologi biasanya berkaitan dengan hal-hal yang bersifat mitos. Mitos oleh manusia dipakai sebagai media komunikasi guna memenuhi kebutuhan non fisik, memberikan pemahaman sesuatu diluar kemampuan manusia untuk memahami suatu fakta yang terjadi, merupakan uraian naratif sesuatu yang sakral, yaitu kejadian-kejadian yang luar biasa di luar pikiran manusia dan mengatasi pengalaman sehari-hari manusia. Di samping itu ornamen juga dapat disebut sebagai alat komunikasi tradisional yang tak langsung sebagai salah satu cara dalam berhubungan dengan sesama maupun dengan penguasa alam semesta. 


\section{Fungsi Ornamen}

Fungsi ornamen adalah untuk menambah keindahan benda. Penerapan ornament pada bangunan tradisional diatur dan disesuaikan dengan bentuk, fungsi serta struktur bendanya sehingga tujuan untuk menciptakan keindahan dan keagungan dapat tercapai. Menurut fungsinya, ornament dapat dibagi dalam tiga bagian, yaitu: (1) ornamen aktif, yaitu ornament yang digunakan pada elemen bangunan, sebagai penghias konstruksi bangunan; (2) ornamen pasif, yaitu ornament yang digunakan pada elemen bangunan, benda-benda pakai lainnya yang berfungsi hanya sebagai hiasan saja; (3) ornamen simbolis, yaitu ornament yang mempunyai makna simbolis atau perlambang (Skinner, 1991).

\section{Ragam Motif Hiasan}

Motif hiasan dengan penggambaran binatang dan tumbuh-tumbuhan tertentu dan dewa-dewa, selain mengandung makna simbolik, juga mengandung unsur-unsur mithologi. Motif hiasan yang bermakna mitos antara lain digambarkan dalam wujud binatang seperti Naga, Qilin, burung merak, macan, dan rusa. Dengan menggunakan lambang-lambang binatang tersebut masyarakat Tionghoa mengharapkan, agar kekuatan dan segala sifat baik yang ada pada binatang mitos tersebut, dapat berpindah dan dimanfaatkan untuk kepentingan mereka.

Unsur-unsur mitos yang berupa tumbuh-tumbuhan juga digambarkan pada motif hiasan berupa bunga teratai, bunga krisan, dan pohon bambu. Karena sifatnya tumbuh-tumbuhan tersebut dianggap sebagai lambang-lambang yang mempunyai sifat-sifat yang sama dengan kelompok masyarakat Tionghoa yaitu mempunyai kekuatan alami antara lain tahan terhadap berbagai perubahan cuaca atau iklim. Sementara itu bambu bagi sekelompok suku di Cina dianggap sebagai asal mula nenek moyang mereka.

Selain hiasan yang berupa binatang dan tumbuh-tumbuhan, terdapat juga lukisan dewa pintu, dianggap sebagai dewa-dewa nenek moyang. Dengan adanya paham mitos tersebut, maka lukisan dewa-dewa nenek moyang diyakini dapat menolak roh-roh jahat. Dengan demikian, mitos sebagai bentuk kepercayaan yang paling elementer, ternyata ditemukan juga pada kelompok Tionghoa. Unsur ini diwujudkan baik pada bentuk hiasan pada kelenteng maupun dalam ritus-ritus pemujaan nenek moyang. Kedua perwujudan unsur mitos tersebut ternyata masih besar peranannya dalam kehidupan sosial budaya Tionghoa hingga sekarang.

Di atas atap selalu ditempatkan sepasang naga yang dibentuk dari porselin dalam kedudukan saling berhadapan untuk berebut sebuah mutiara alam semesta menyala, lambang matahari $(\mathrm{Cu})$. Pada bagian atap bangunan yang lain dihiasi sepasang naga mengapit $H o$ Lo, yaitu buah labu yang telah kering sebagai tempat air/arak. Ho Lo tidak dapat dipisahkan dari bekal para dewa, sehingga dianggap punya kekuatan gaib untuk menjaga keseimbangan Hong Shui dan menangkal hawa jahat.

\section{PEMBAHASAN}

\section{Ornamen pada Atap Bangunan Utama Klenteng}

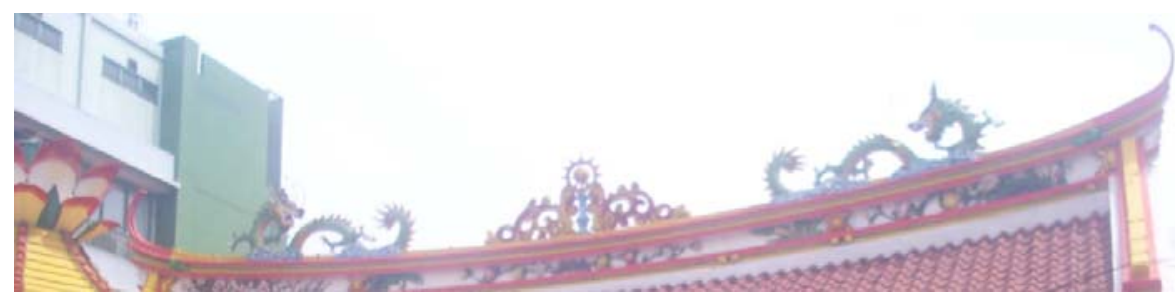

Gambar 2 Atap Klenteng Jin de Yuan bagian depan

Sumber: Dokumen pribadi 


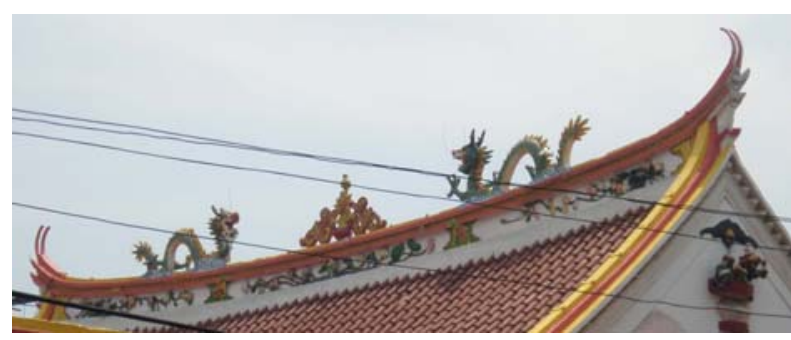

Gambar 3 Atap Klenteng Jin de Yuan bagian belakang Sumber: Dokumen pribadi

Pada atap bangunan utama bubungannya berbentuk ekor walet, tampak 2 patung keramik naga yang menari berhadap-hadapan dengan patung buah labu air atau ho lo (shiolo) berada diantara kedua naga, hal ini melambangkan kekuatan dan tenaga dari dewa-dewa. Pada foto atap gedung utama sisi depan, posisi badan naga membelakangi shiolo dan muka menghadap shiolo dengan mutiara alam semesta (cu) diatas shiolo. Sedangkan kedua naga pada atap gedung utama sisi belakang saling menghadap shiolo.

Di bagian pinggang atap tampak relif motif tanaman perdu dan bunganya, yang melambangkan panjang umur dan keabadian. Warna kuning atau emas - secara geomantic diungkapkan sebagai warna surga atau nirvana. Warna merah sebagai kombinasinya yang kontras melambangkan kegembiraan dan kesenangan.

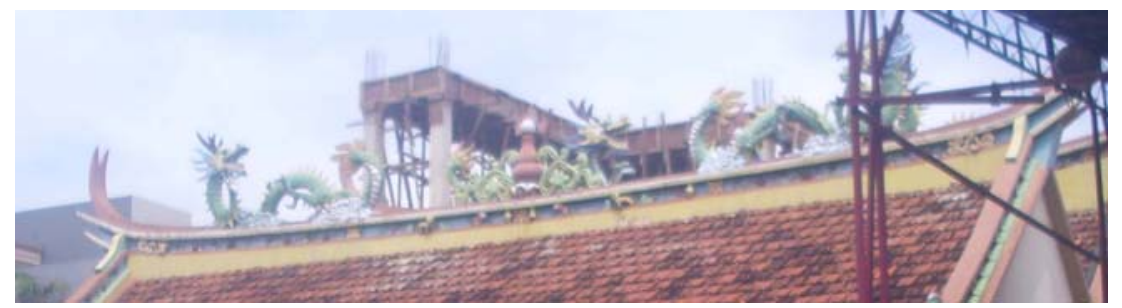

Gambar 4 Atap Kelenteng Hui-ze Miao

Sumber: Dokumen pribadi

Pada atap bangunan kelenteng Hui-ze Miao bubungannya berbentuk ekor wallet seperti atap Kelenteng Jin de yuan, tetapi perbedaan pada bentuk 2 patung keramik naga yang menari membelakangi patung buah labu air atau hu lu (shiolo) yang berada diantara kedua naga, namun berpaling menghadap kearah labu air. Hal ini melambangkan kekuatan dan tenaga dari dewa-dewa.

\section{Ornamen pada Atap Gapura}
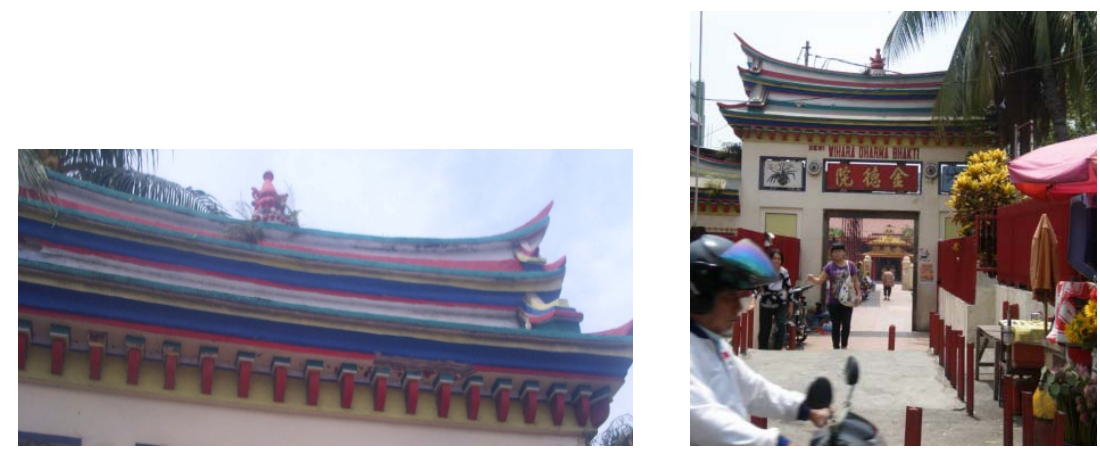

Gambar 5 Atap gapura utama

Sumber: Dokumen pribadi 
Patung buah Labu atau ho lo (shiolo), berada tepat ditengah-tengah nok gapura utama. Hal ini dipercaya sebagai kekuatan untuk menjaga lingkungan dari pengaruh jahat yang hendak masuk merusak atmosfir Klenteng. Warna-warna merah, kuning, hijau, biru dan putih melambangkan keselarasan, kemashuran, kegembiraan dan kesucian surga (Lip, 1988).
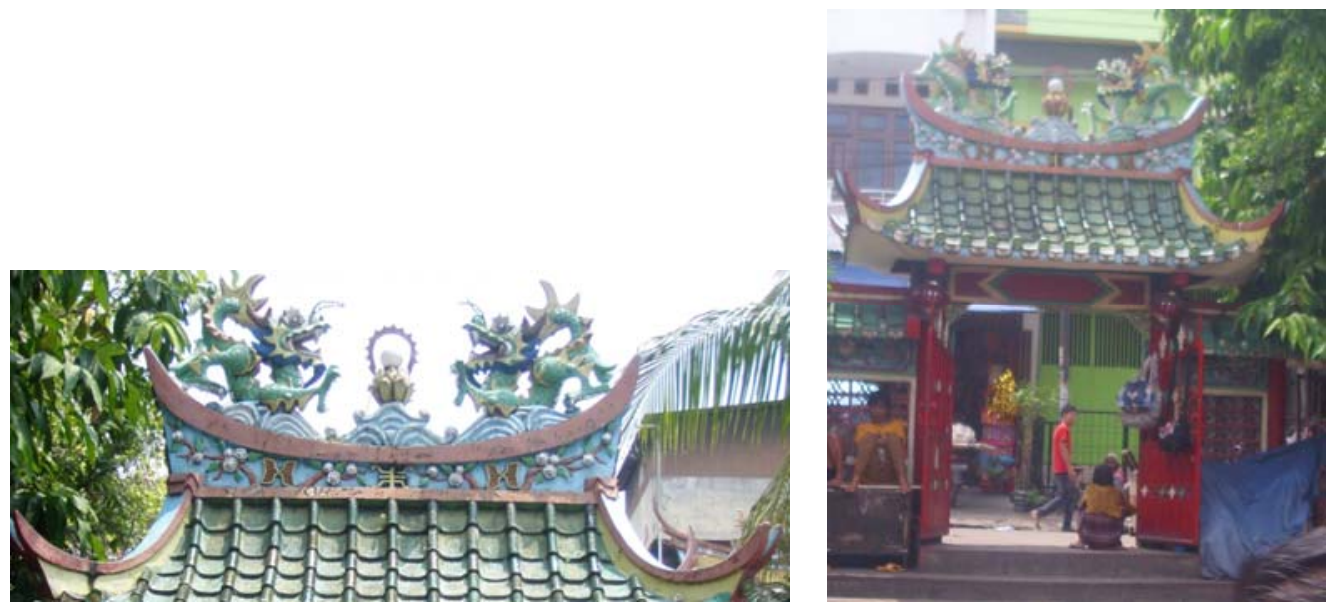

Gambar 6 Gapura sisi timur menuju Kelenteng Hui ze Miao Sumber: Dokumen pribadi

Di atas atap gapura samping sisi Timur menuju kelenteng Hui ze Miao ditempatkan sepasang naga yang dibentuk dari porselin dalam kedudukan saling berhadapan dengan cakar saling mengancam untuk berebut sebuah mutiara alam semesta menyala, lambang matahari $(\mathrm{Cu})$., sehingga dianggap punya kekuatan gaib untuk menjaga keseimbangan Hong Shui dan menangkal hawa jahat. Warna gapura lebih didominasi warna hijau yang melambangkan panjang umur dengan pengharapan lingkungan klenteng ini dapat lestari sepanjang masa.

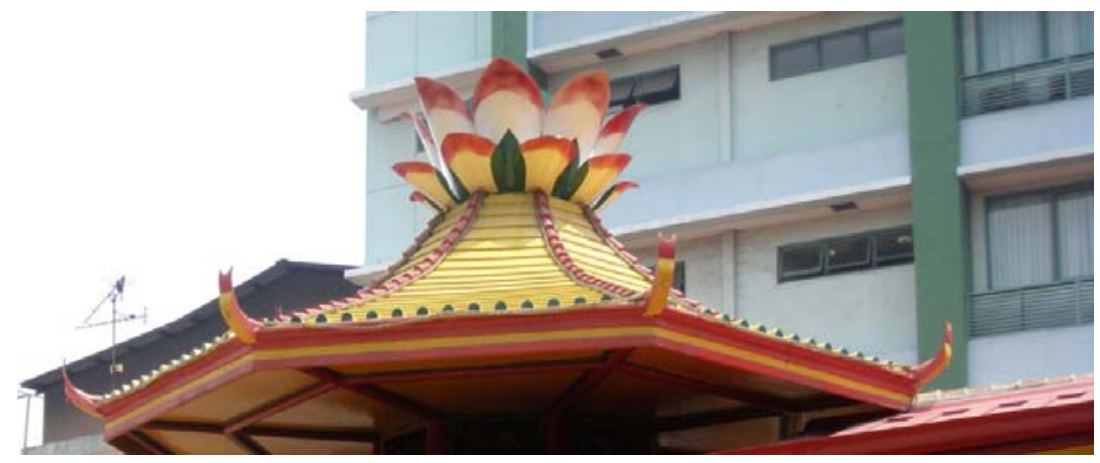

Gambar 7 Atap Thi Kong

Sumber: Dokumen pribadi

Atap ini sudah perbahuruan dari bangunan aslinya yang telah lapuk. Tampak ornamen bunga teratai diatapnya yang melambangkan keindahan dan kekuatan untuk melawan kekejaman iklim. Bunga teratai dalam agama Budha dipercaya sebagai tempat duduk Sang Budha yang melambangkan keagungan. Tempat ini digunakan sebagai penyembahan kepada Tuhan atau Thian, dengan cara membakar hio dan asapnya yang membumbung kelangit diharapkan dapat membawa segala doa dan pengharapan yang dipanjatkan. 


\section{PENUTUP}

Keinginan untuk mencapai nilai-nilai hidup menuju kesempurnaan (kesehatan, panjang umur, kekuatan, kemakmuran, dan perlindungan terhadap segala bahaya) dimaknai melalui simbol-simbol mahluk hidup dan warna yang diaplikasikan pada berbagai elemen bangunan klenteng. Melihat ragam hias pada atap klenteng Jin De Yuan dapat kita simpulkan bahwa nilai budaya dapat diterapkan pada elemen eksterior bangunan, yang dapat menambah nilai keindahan dari kelenteng. Dengan tetap terjaganya kelestarian dan keindahan ornamen pada bangunan klenteng, dapat menjadi satu nilai positif bagi kelangsungan klenteng sebagai salah satu bagian dari kawasan kota tua yang merupakan aset negara. Kendala yang dihadapi dalam hal peran serta desainer dalam mengolah ragam hias klenteng adalah keterbatasan ruang gerak oleh karna koridor yang mengikat, berupa aturan dan batasan yang berhubungan dengan religi serta kebudayaan dalam klenteng tersebut. Namun diharapkan, bila terjadi revitalisasi kota tua, para desainer tetap dapat memegang peranan penting demi pelestarian aset negara ke depannya.

\section{DAFTAR PUSTAKA}

Lip, E. (1988). Letak dan arah bangunan yang membawa keberuntungan. Jakarta: Bina Pustaka.

Skinner, S. (1991). Ilmu tata letak tanah dan kebudayaan Cina kuno. (D. Prize, terj.). Semarang. 